\title{
Development of a Passive Check Valve for Cryogenic Applications
}

\author{
Bradley Moore ${ }^{1}$ \\ University of Wisconsin - Madison
}

\begin{abstract}
Future astrophysics missions will rely on a new generation of cooling technologies to improve the resolution of infrared and x-ray sensors. A novel continuous cold cycle dilution refrigerator (CCDR) has been proposed by Prof. F.K. Miller to provide cooling for these sensors at temperatures below $100 \mathrm{mK}$. A passive check valve for liquid ${ }^{4} \mathrm{He}-{ }^{3} \mathrm{He}$ mixtures is a key technological innovation required to implement the CCDR, as will be further explained in the paper. The design of a reed style passive check valve and initial results from tests with helium gas at room temperature and $80 \mathrm{~K}$ will be detailed.
\end{abstract}

\section{Introduction}

Cooling for space science instruments to temperatures below 1 Kelvin is critical for new infrared and $\mathrm{x}$-ray astrophysics missions. The cutting edge in detector technology for infrared missions lies in cryogenic detectors, either transition edge sensor (TES) bolometers or microwave kinetic inductance detectors (MKIDs). Future $\mathrm{x}$-ray missions that include spectrometers will include microcalorimeters that also need to be cooled to temperatures below $1 \mathrm{~K}$. Each of these detector types requires operation at sub-Kelvin temperatures for the highest sensitivity applications. The sub-Kelvin continuous cooling needed for these missions is achievable with the dilution refrigerator that is detailed in this report.

Current space flight technologies used to obtain sub-Kelvin temperatures are the Adiabatic Demagnetization Refrigerator (ADR), the single shot, space-pumped dilution refrigerator and the ${ }^{3} \mathrm{He}$ evaporation refrigerator. Prof. F. K. Miller has proposed a novel a cold cycle dilution refrigerator (CCDR) using a novel thermal magnetic pump capable of cooling to temperatures below $100 \mathrm{mK}$. This innovative technology will provide cooling at temperatures below $100 \mathrm{mK}$ for detectors on future infrared and x-ray astrophysics missions and will, in turn, enable NASA to better fulfill strategic sub-goal 3D: to discover the origin, structure, evolution and destiny of the universe, and search for Earth-like planets.

The initial scope of the proposed research for the Wisconsin Space Grant Consortium Fellowship was to fabricate and test a Cold Cycle Dilution Refrigeration system. However, upon becoming more familiar with the project, it quickly became clear that the scope of such an endeavor was far beyond the year indicated in the fellowship proposal, or even the 2 years in an M.S. program. Given the level of complexity and expectations of the primary funding source (NASA SBIR Phase 1 grant), the work accomplished in the tenure of the fellowship was focused on a crucial component and major technological hurdle to the CCDR development: the cold check valves.

\section{Cold Cycle Dilution Refrigerator}

Special acknowledgement to Prof. F.K. Miller, Prof. J. M. Pfotenhauer of UW-Madison and Dr. J. Maddocks of Atlas Scientific for their intellectual support and the Wisconsin Space Grant Consortium for financial support. 
System. The cold cycle dilution refrigerator will consist of a pump, two recuperative heat exchangers, a phase separation chamber, a mixing chamber and a throttle. The cycle was modeled by an M.S. student working for Prof. Miller, Bryant Mueller.

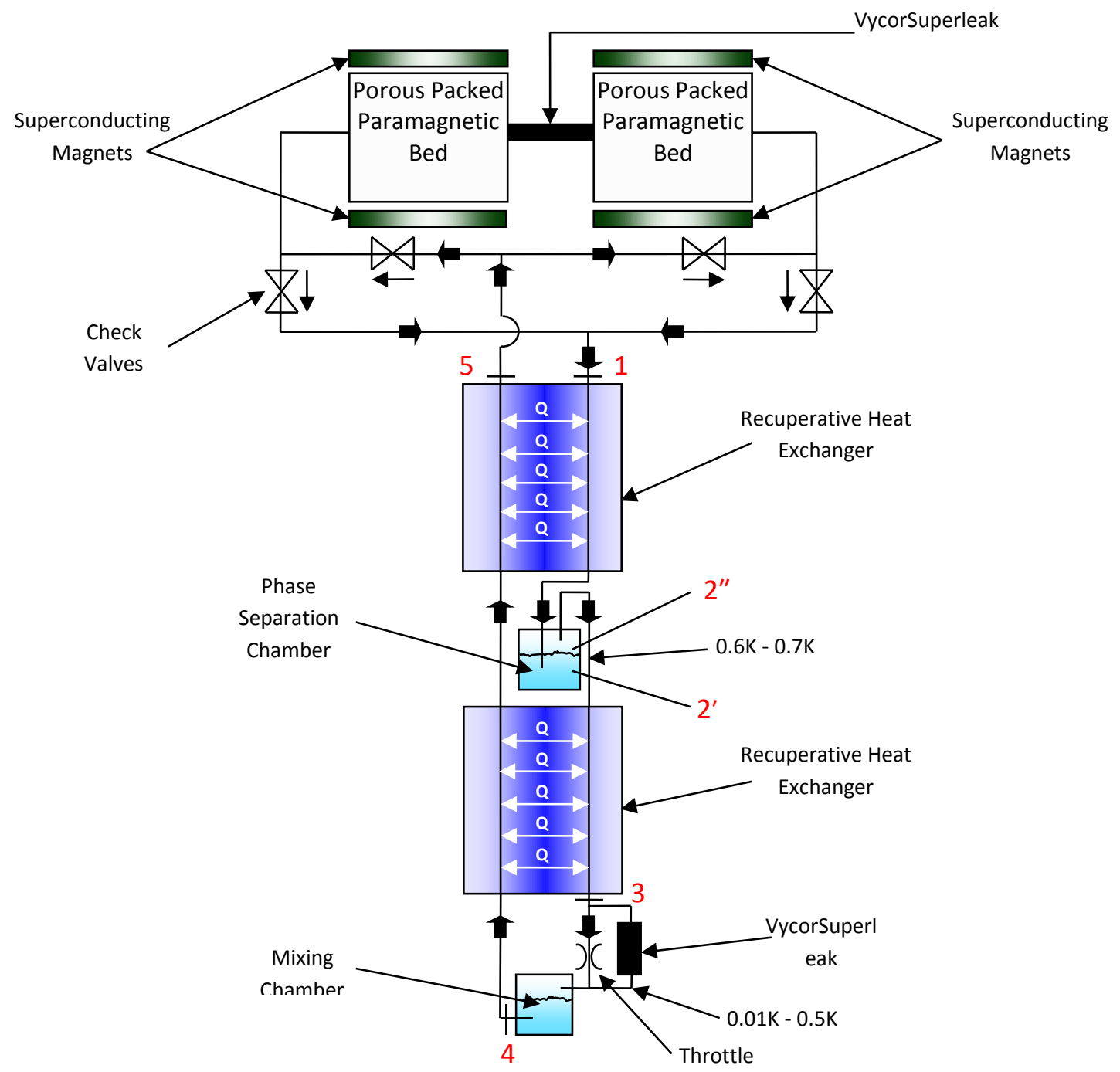

Figure 1. Schematic of the cold cycle dilution refrigerator.

A mixture of ${ }^{3} \mathrm{He}$ and ${ }^{4} \mathrm{He}$ with a concentration of approximately $6 \%{ }^{3} \mathrm{He}$ exits the pump at 1.7 Kelvin and flows into a recuperative heat exchanger. The pump itself is a thermodynamically reversible fountain effect pump invented by Professor Miller and currently being developed at the University of Wisconsin (Miller 2009). In this heat exchanger the fluid is cooled as it exchanges heat with the low concentration stream. As the high concentration stream is cooled it follows a line of constant ${ }^{4} \mathrm{He}$ chemical potential as shown in Fig. 2. Therefore, the concentration of the high concentration stream increases as the temperature decreases through the recuperator. (Note: the labels on Fig. 2 correspond to the labeled positions on Fig. 1.) The working fluid exits the cold end of the recuperator as a 2-phase mixture and enters a separation 
chamber where the ${ }^{3} \mathrm{He}$ rich phase is separated from the ${ }^{4} \mathrm{He}$ rich phase, creating a ${ }^{3} \mathrm{He}$ concentrate and $\mathrm{a}^{3} \mathrm{He}$ dilute phase. For ground- based applications this separation can be achieved by gravity due to the density difference between the phases. For operation in microgravity, surface tension forces will be used to accomplish the separation. Dilution refrigerators that use surface tension for phase separation have been developed at the NASA Ames Research center (Roach 1999). Further developmental work is required to verify this.

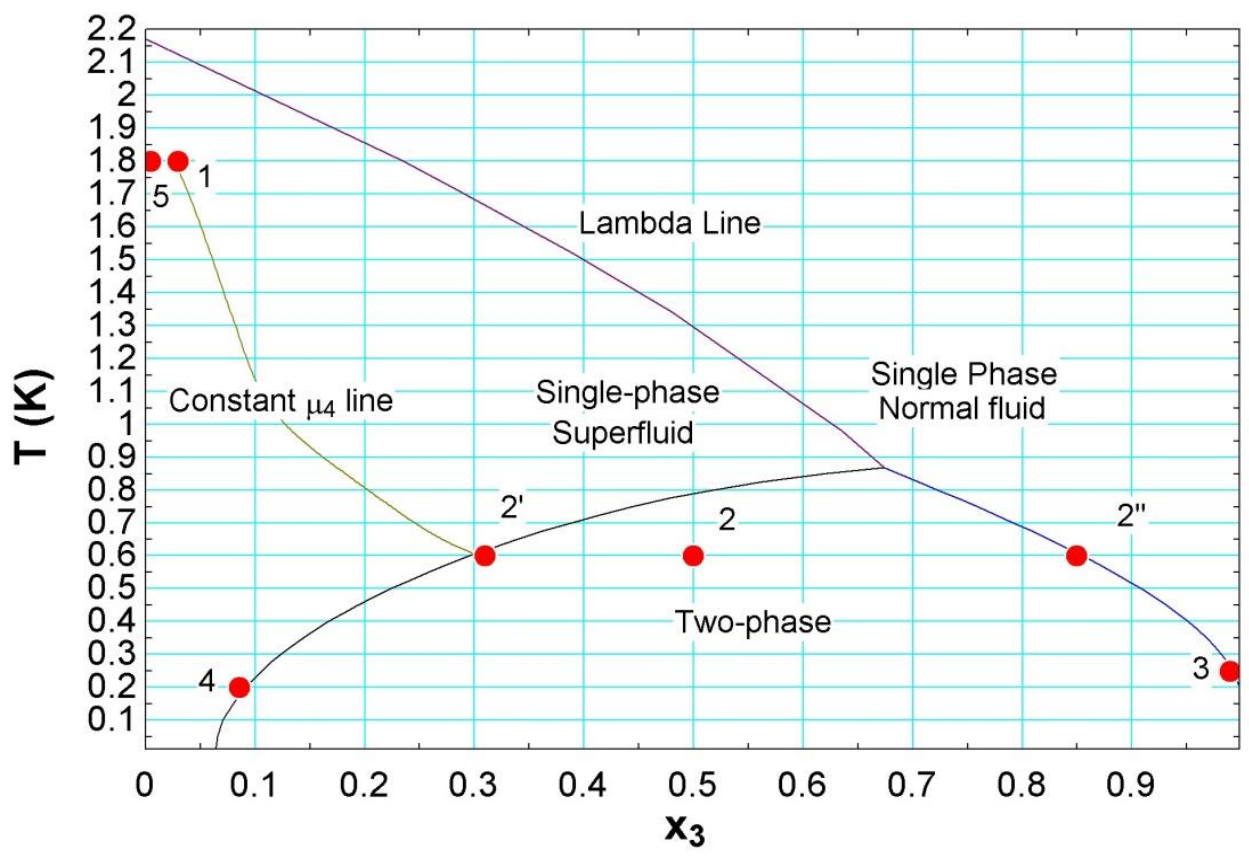

Figure 2. Plot of the cold cycle dilution refrigerator cycle on a $\mathrm{T}-\mathrm{x}_{3}$ diagram.

Next, the ${ }^{3} \mathrm{He}$ rich phase exits the separation chamber and enters another recuperative heat exchanger and is cooled by the low concentration stream. Then the fluid passes through a capillary where the pressure drops. The high ${ }^{3} \mathrm{He}$ concentration mixture enters a mixing chamber and is diluted with ${ }^{4} \mathrm{He}$. The process of mixing ${ }^{3} \mathrm{He}$ into ${ }^{4} \mathrm{He}$ is endothermic therefore heat is absorbed from the load, providing the primary cooling at sub Kelvin temperatures. Low ${ }^{3} \mathrm{He}$ concentration mixture exits the mixing chamber and returns to the pump via the two recuperative heat exchangers.

At Goddard, Miller developed a thermodynamically reversible fountain effect pump shown in Fig. 3 (Miller 2009). The pump consists of two canisters packed with Gadolinium Gallium Garnet (GGG) spheres connected by a piece of Vycor glass, called a superleak. A superconducting magnetic coil surrounds each of the canisters. The operation of the pump can be simplified into 4 primary steps shown in Table 1 . The current in the coil around cylinder $\mathrm{A}$ is increased while the current in cylinder B is decreased. This causes the magnetic field in A to increase while the magnetic field in B decreases. As the field increases in the paramagnetic GGG spheres the magnetic entropy decreases causing the thermal entropy in the spheres and the surrounding fluid to increase (the temperature increases) consistent with process step I. At the same time the field in the other bed is decreasing so the temperature of the spheres and fluid in the other bed decreases. The temperature gradient across the superleak results in a 
pressure gradient that causes the configuration to act like the well-known fountain effect pump. When the pump contains a dilute mixture of ${ }^{3} \mathrm{He}-{ }^{4} \mathrm{He}$, the low temperature side is gradually depleted of ${ }^{4} \mathrm{He}$ because the ${ }^{4} \mathrm{He}$ flows out through the superleak to the high temperature side while the ${ }^{3} \mathrm{He}$ is blocked by the superleak staying behind at the cold side during the second process step.

\begin{tabular}{lllll}
\hline $\begin{array}{l}\text { Process } \\
\text { Step }\end{array}$ & $\begin{array}{l}\text { Process } \\
\text { Description }\end{array}$ & $\begin{array}{l}\text { Pump } \\
\text { Concentration }\end{array}$ & $\begin{array}{l}\text { Pump } \\
\text { Temperature }\end{array}$ & Magnetic Field \\
\hline I. & $\begin{array}{l}\text { Raise temp at } \\
\text { constant } \\
\text { concentration }\end{array}$ & High & $\begin{array}{l}\text { Rapidly } \\
\text { increasing }\end{array}$ & $\begin{array}{l}\text { Rapidly } \\
\text { increasing to } \\
\text { intermediate }\end{array}$ \\
II. & $\begin{array}{l}\text { Discharge }{ }^{3} \mathrm{He} \text { at } \\
\text { constant temp }\end{array}$ & Decreasing & High & $\begin{array}{l}\text { Ramp increase } \\
\text { to maximum }\end{array}$ \\
III. & $\begin{array}{l}\text { Lower temp at } \\
\text { constant } \\
\text { concentration } \\
\text { Replenish }{ }^{3} \mathrm{He} \text { at } \\
\text { constant temp }\end{array}$ & Low & $\begin{array}{l}\text { Rapidly } \\
\text { decreasing }\end{array}$ & $\begin{array}{l}\text { Rapidly } \\
\text { decreasing to } \\
\text { intermediate }\end{array}$ \\
IV. & Increasing & Low & $\begin{array}{l}\text { Ramp decrease } \\
\text { to zero }\end{array}$ \\
\hline
\end{tabular}

Table 1. Pumping Process description

Eventually the cold side ${ }^{4} \mathrm{He}$ content drops to the point that it becomes necessary to reverse the direction of flow, which is accomplished by simply reversing the direction of the current in the superconducting magnetic coils, entering into process step III for cylinder A, and process step I for cylinder B. This causes the magnetic field and hence the temperature of the warmer bed (A) to begin decreasing while the field and temperature of the colder bed (B) begin increasing, thus reversing the direction of the pumping action and leading into step IV, when the ${ }^{3} \mathrm{He}$ is replenished in cylinder $\mathrm{A}$ and depleted from cylinder $\mathrm{B}$. This configuration allows cyclic thermodynamic cycles to be driven without using pistons or moving parts.

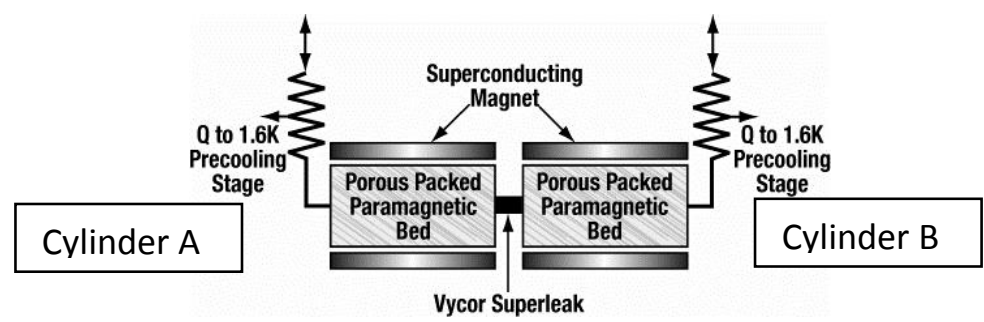

Figure 3. Schematic of the reversible pump.

Because of the requirement that the flow be reversed periodically, the pump is inherently an alternating flow device. However, it can be adapted to work with continuous flow thermodynamic cycles such as the superfluid Joule-Thomson cycle and the proposed cold cycle dilution refrigerator by adding low temperature check valves, as shown in Fig. 1, to rectify the alternating flow. 
Check Valve Requirements. The operation of the check valves in the system is best illustrated by a series of diagrams, Fig. 4 to 7 . Gray valves are sealed; black valves are open, with arrows to indicate flow direction.

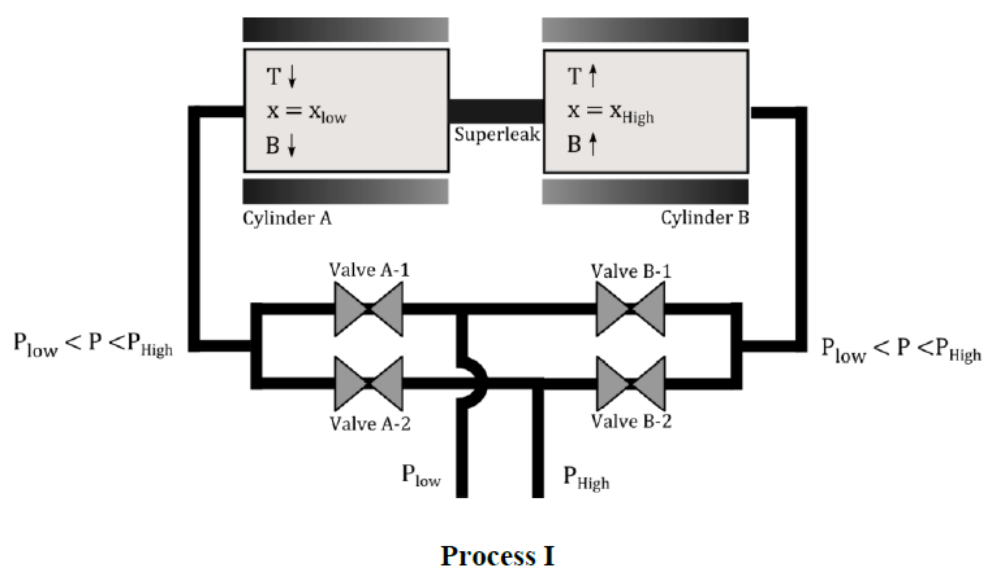

Figure 4. Process I, Cylinder A: Lowering temp at constant concentration, $\mathrm{P}_{\text {low }}<\mathrm{P}_{\mathrm{A}}<\mathrm{P}_{\text {high, }}$ ylinder B: Raising temp at constant concentration, $\mathrm{P}_{\text {low }}<\mathrm{P}_{\mathrm{B}}<\mathrm{P}_{\text {high }}$

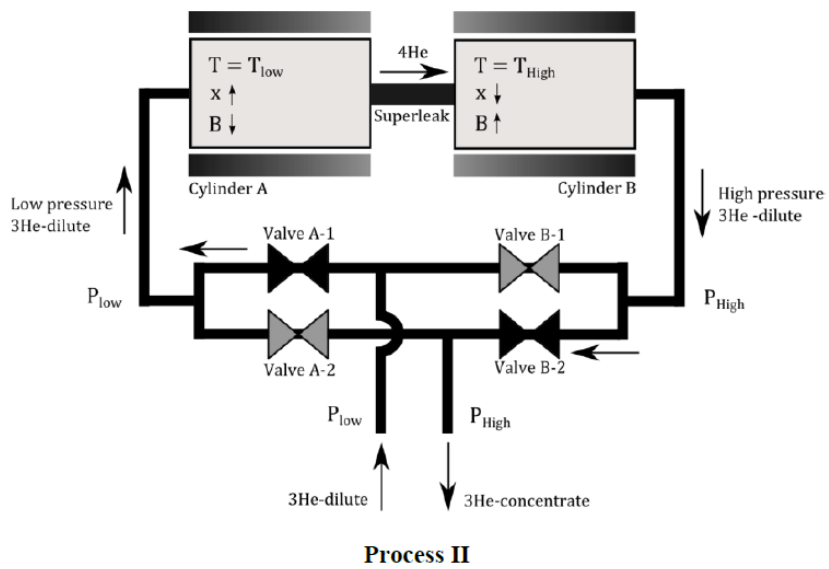

Figure 5. Process II, Cylinder A: Replenish ${ }^{3} \mathrm{He}$ at constant temp, $\mathrm{P}_{\mathrm{A}}=\mathrm{P}_{\mathrm{low}}$, Cylinder B: Discharge ${ }^{3} \mathrm{He}$ at constant temp, $\mathrm{P}_{\mathrm{B}}=\mathrm{P}_{\text {high }}$

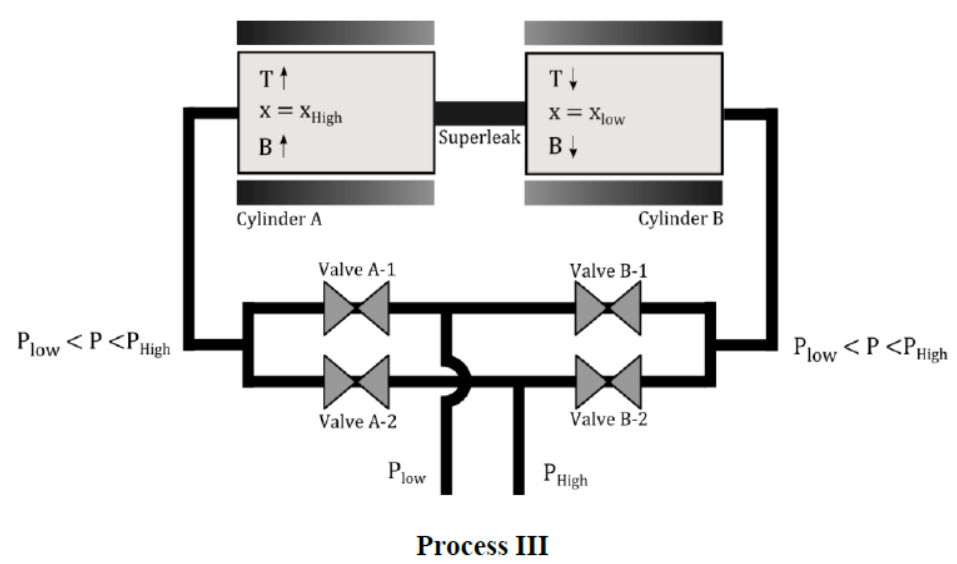

Figure 6. Process III, Cylinder A: Raising temp at constant concentration, $\mathrm{P}_{\text {low }}<\mathrm{P}_{\mathrm{A}}<\mathrm{P}_{\text {high }}$, Cylinder B:

Lowering temp at constant concentration, $\mathrm{P}_{\text {low }}<\mathrm{P}_{\mathrm{B}}<\mathrm{P}_{\text {high }}$ 


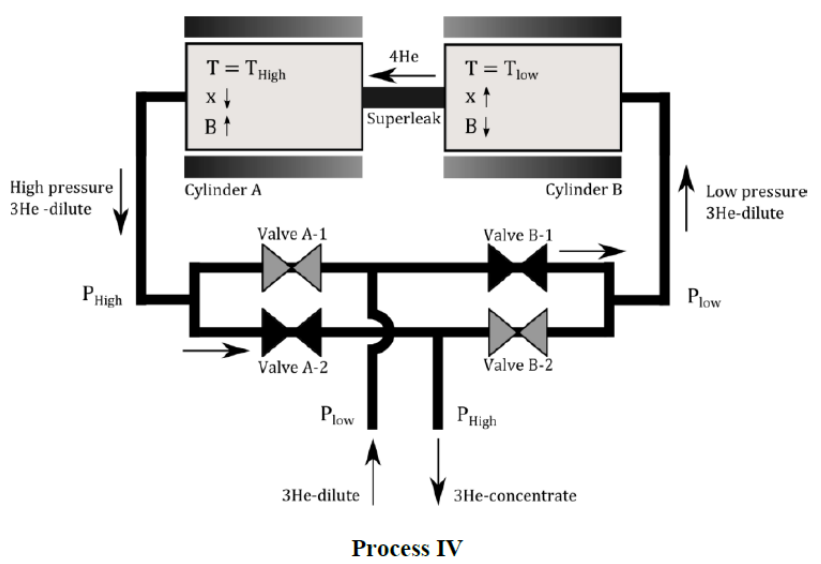

Figure 7. Process IV, Cylinder A: Discharge ${ }^{3} \mathrm{He}$ at constant temp, $\mathrm{P}_{\mathrm{A}}=\mathrm{P}_{\text {high }}$, Cylinder B: Replenish ${ }^{3} \mathrm{He}$ at constant temp, $\mathrm{P}_{\mathrm{B}}=\mathrm{P}_{\text {low }}$

It is clear from these diagrams that the check valves must seal to flow in one direction, but open to a very low pressure differential in the opposite direction.

After much of the testing had been done on the check valve, the numerical model of the system was completed. This gave a much more accurate picture of the high pressure and low pressure requirements of the valve. When the initial development was done, it was assumed that the pump would achieve a pressure differential of $10 \mathrm{psi}$. However, the final model results indicated that the pump would only achieve approximately 1.4-3.2 psi. Since much of the initial work was done with 10 psi, this was kept as the sealing pressure criteria for further understanding the valve. Once a functional valve for $10 \mathrm{psi}$ is accomplished and understood, it will be possible to optimize for a lower pressure as will be discussed later. The model also indicated forward flow rates ranging from $60-140 \mu$ mole $/ \mathrm{s}^{3} \mathrm{He}(1.800 \mathrm{E}-07$ to $4.200 \mathrm{E}-07 \mathrm{~kg} / \mathrm{s})$. Since ${ }^{3} \mathrm{He}$ is extremely costly and currently tightly rationed by the DOE, the tests were done with ${ }^{4} \mathrm{He}$.

Check valve design. The initial design of the valve was based on Miller's work at MIT (Miller 1999). Polymers such as Teflon (PTFE) exhibit creep at higher temperatures, but "freeze" into shape at lower temperatures. Therefore some preload can be applied at room temperature to cause the Teflon to creep and match the sealing surface of the valve. When the valve is cooled to cryogenic temperatures, the preload is released and the Teflon will hold the sealing surface shape, giving repeatable sealing.

The initial valve was a poppet design with spring preload; however the preload required was sufficiently high such that the spring could not provide sufficient sealing. There were also other issues associated with the geometry and possible gravity effects that drove a move to different valve geometry. Based on Dr. Maddocks' experience with metal seated cryogenic reed valve and Miller's experience with polymer seats, a new valve was designed. This used the reed valve design with a Teflon seat. It eliminates the gravity issues and provides a baseline with a wellknown geometry. Fig. 8 shows an exploded section view of the valve of the fabricated valve, Fig. 9 shows a picture of the valve.

The Teflon seat is epoxied over the base with Stycast 1266, chosen for its performance at low temperatures. Also, given Teflon's resistance to bonding, inner diameter of the bonding surface 
must be etched with a chemical etchant. The spring steel reed is placed on top of the seat. The copper washer and wave spring hold the reed in place over the valve. The flow direction is indicated by the arrow.

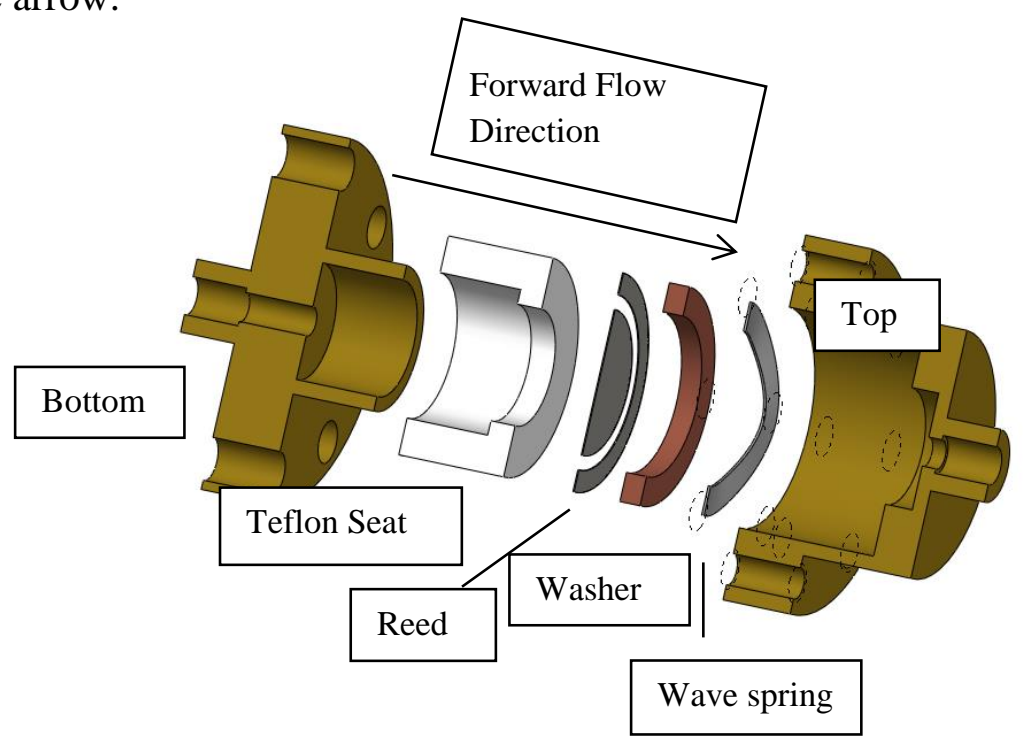

Figure 8. Exploded section view of reed style check valve

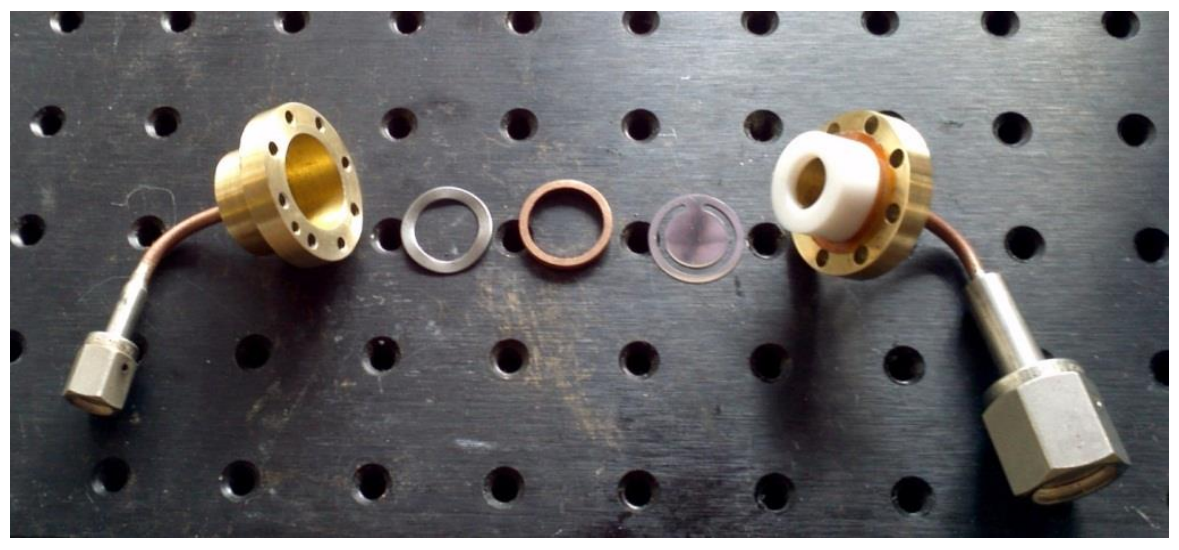

Figure 9. Picture of actual reed check valve

\section{Experiment}

Test Setup. For actually testing the valve, a liquid helium test would be ideal but the deadline for the NASA SBIR was approaching so a simpler alternative needed to be developed. A Nitrogen test was adopted since material properties (thermal contraction, Teflon workability) change little below approximately $100 \mathrm{~K}$. This allowed for a simple procedure:

-Lower experiment into open, empty LN2 dewar

-Apply pressure to valve if preloading

-Fill dewar from large storage tank until valve and coil completely covered with LN2

-The valve has reached LN2 temp when LN2 no longer boiling around valve

-If preloaded with pressure, release the pressure and commence testing 
To measure the flow, an Omega flow meter was employed, with a range of 0-2 slpm (0 to 5.5E-6 $\mathrm{kg} / \mathrm{s} \mathrm{He}$ ) and a resolution $\sim 4 \mathrm{E}-9 \mathrm{~kg} / \mathrm{s} \mathrm{He}$. For lower flow rates, a Bubble flow meter was employed to give a resolution of $\sim 8.915 \mathrm{E}-12 \mathrm{~kg} / \mathrm{s}$. For pressure sensors, Endevco pressure transducers with a range of 0-300 psi and a resolution of $\sim .01$ psi where utilized.

Results. The first phase of testing was to achieve sealing to backflow (flow opposite the forward flow direction discussed earlier) at room temperature. However, a 10 psi pressure difference at room temp resulted in flow above the range of the flow meter $(\sim 5.5 \mathrm{E}-6 \mathrm{~kg} / \mathrm{s})$. The pressure was increased until the valve sealed at room temperature with a pressure difference of $25 \mathrm{psi}$. The experiment was then cooled down with that pressure as the preload. The pressure was released after cool down and the flow rate at different pressures was recorded. Since better sealing was seen at higher pressures at room temperature, the valve was warmed up and cooled down with 45 psi and 65 psi respectively and the low temperature flow rates were recorded at that temperature. The results are compared to the theoretical forward flow rate of the valve shown in Fig. 10.

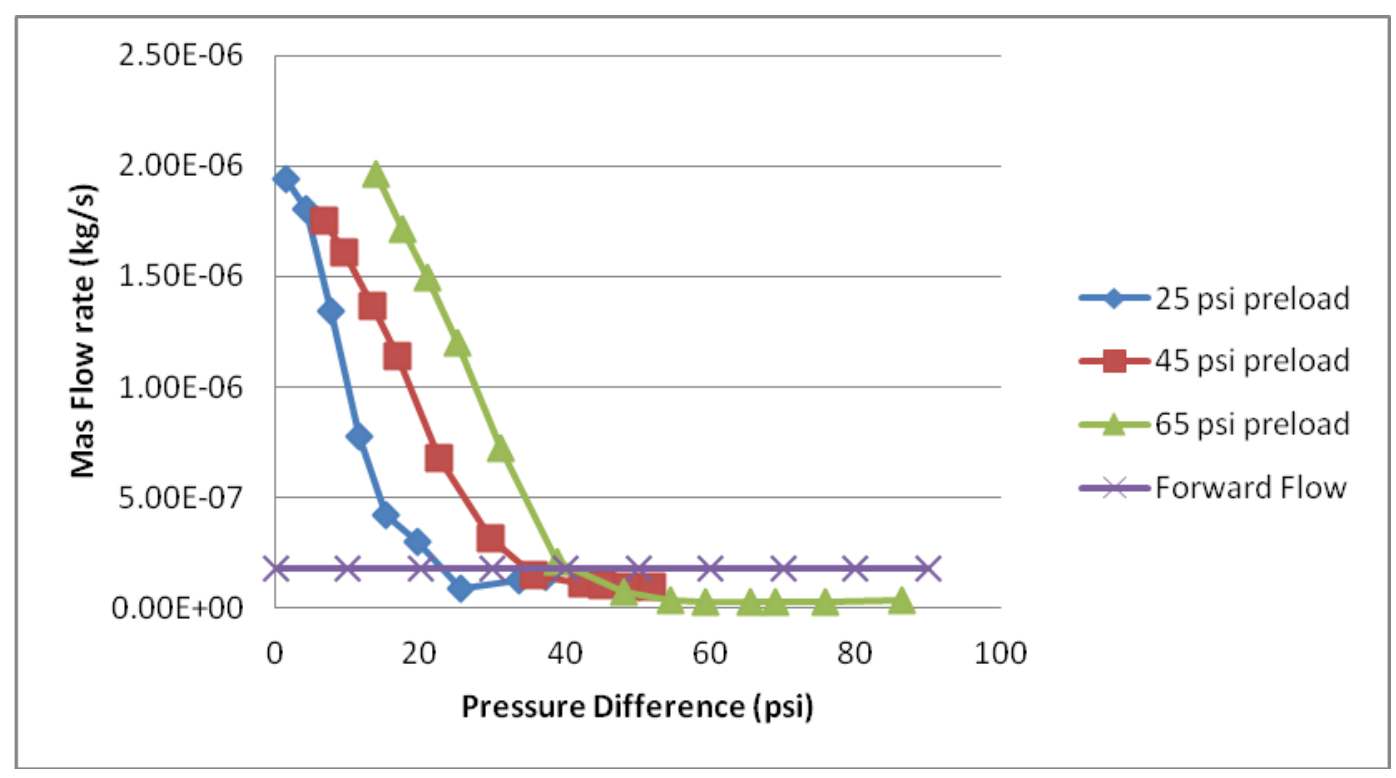

Figure 10. Cold back flow mass flow rates compared to theoretical forward flow

After the pressure is released, the minimum leak back is still at that pressure. Also, sealing improves at higher pressures but after cool down the sealing is poor at low pressures. Higher pressures freeze a small radius of curvature into the Teflon seat. When the high pressure is released at low temperature and lower pressures are tested, the radius of curvature no longer matches. The data suggest that a balance is needed between a preload pressure that will smooth out asperities, but will still have a curvature near that of the reed at low pressures. It is well known that the radius of curvature of a simply supported thin circular plate with a uniformly applied load is proportional to the cube of its thickness. Based on this, the radius of curvature of a 4 mil thick reed at a pressure difference of 10 psi is expected to be the same as the radius of curvature of an 8 mil thick reed at a pressure difference of 80 psi. Therefore, a well-polished 8 mil reed can be pressurized to $80 \mathrm{psi}$ at room temperature to permanently smooth asperities while still maintaining the radius of curvature that a 4 mil reed would possess at 10 psi. Fig. 11 shows 
that this was very successful with flow rates below the forward flow even when no preload was applied. Even better results were accomplished with a preload.

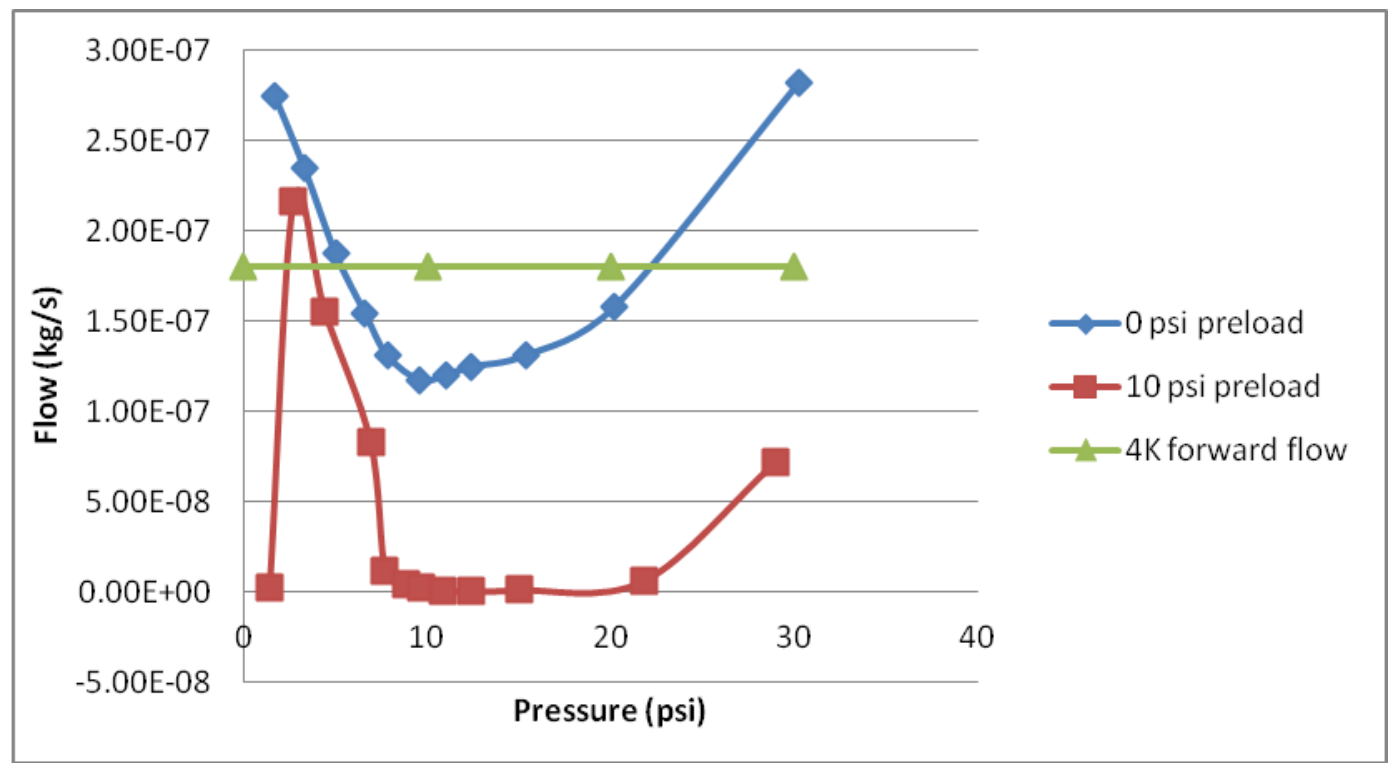

Figure 11. Preformed Cold back flow mass flow rates compared to theoretical forward flow

\section{Conclusion}

In conclusion, the back flow rates are in an acceptable range for application in a CCDR. Further investigation is required before the valve can be considered a complete success. The actual CCDR will have a lower pressure difference than was tested. The fluid that must be sealed against will not be ${ }^{4} \mathrm{He}$ gas at liquid nitrogen temperatures, but the ${ }^{3} \mathrm{He}$ component in a ${ }^{3} \mathrm{He}-{ }^{4} \mathrm{He}$ mixture at liquid helium temperatures. Currently, a liquid helium temperature test by using a Stirling Cryocooler that will improve the confidence in this design is being pursued. However, there remains a strong indication from the data that a reed-style passive check valve can be optimized for use in a cold cycle dilution refrigerator.

\section{References}

[1] F.K. Miller and J. G. Brisson, A Superfluid Pulse Tube Driven by a Thermodynamically Reversible Magnetic Pump, Cryocoolers 15, Proceedings of the 15th International Cryocooler Conference (2009).

[2] Pat R. Roach and Ben P.M. Helvensteijn, Progress on a Microgravity Dilution Refrigerator, Cryogenics 39 (1999) pp. 1015-1019.

[3] Franklin K. Miller, J.G. Brisson, Development of a low-dissipation valve for use in a coldcycle dilution refrigerator, Cryogenics, Volume 39, Issue 10, 12 October 1999, Pages 859863 